From students of Aarhus University with expressed support of the faculty.

This letter pertains to the article "The association between early career informal mentorship in academic collaborations and junior author performance” by Bedoor AIShebli, Kinga Makovi, and Talal Rahwan.

Dear Dr. Elisa De Ranieri,

The authors of this letter represent a large student body who have generally had especially positive experiences with female mentors' advice and mentorships and do not support the conclusions of the article "The association between early career informal mentorship in academic collaborations and junior author performance" because its conclusions regarding gender reach beyond the article's scope and because the quality of mentorships cannot be analysed only through citation counts. Publications are not equivalent to learning outcomes or professional advancement.

After careful review of the aforementioned article, we see numerous scientific flaws. The causal inferences that can be drawn from the observed effects of gender on the mentor-protégé relationship are insubstantial and other aspects of the paper are limited in the reductionist design of their mentor-protégé relationship assessment, which is based on the scientific impact of future papers.

\title{
Methodological criticism:
}

First of all, the conclusions drawn on gender's effects on mentor-protégé relationships are subject to major methodological criticism. Gender is represented as the main effect after controlling for six other variables, specifically the "protégé's average big-shot experience, number of mentors, gender, discipline, affiliation rank, and the year in which they published their first mentored paper" in a Coarsened Exact Matching (CEM) model [1].

The authors represent the many confounders with a single binary variable, using gender as a main effect to explain the remaining data variance, thereby capturing a large amount of undefined signal and noise as a single signal of the protégé and mentor gender's effect. This is problematic because these confounders of the gender effect include, but are not limited to, starting age, funding biases, types of collaboration with co-authors, maternity leave's effect on differences between their categorised early and late career stage scientists, journal publishing biases [2], cultural biases in STEM [3], and the differing experiences of male and female scientists [4]. Aforementioned effects are not adequately captured even with the CEM's more intuitive causal inference properties based on direct matching of similar individuals [1].

Beyond this purely statistical point, it is reductionist to assume that co-authorship in a specific time window is the same as mentorship. Let us elucidate this point further:

We see that the paper has amassed 3 million pairs of protégés and mentors. The paper notes that they want to "provide further evidence that the mentor supported the protégé in ways related not only to the paper on which they are collaborating, but also to career development in general" and verifies the data with surveys sent to a subset of the pairs. 
The surveys were sent by email to 2000 of the identified protégés (around $0.07 \%$ of the identified pairs). Of the 2000 protégés who received verification emails, 167 completed the survey (or around $0.007 \%$ of the identified pairs). In the supplementary information for the article [5], the authors write that 97 of the 167 responses they received stated that "the identified senior collaborator was not their thesis advisor nor a member of their thesis committee".

It is unclear whether the aforementioned 97 respondents proceeded to fill out the survey with regards to their real mentors or with regards to the misidentified mentor. However, it is significant that the validation for the 3 million automatically identified protégé and mentor pairs that 97 out of 167 , or around $58 \%$, were misidentified. The only information available about the quality of the data is thereby that it is valid in around $42 \%$ of $0.007 \%$ of the cases.

They note that the survey is meant to further elucidate the mentor-protégé relationship but as it is unclear if they responded regarding their co-author or their real mentor, which makes it hard to generalize the results of the survey and use its results to explain the rest of the data, as the authors argue. It is problematic that the paper does not note the misidentification rate in the surveys and that it is only available in the supplementary information.

Furthermore, using citations as a proxy for scientific impact could be considered acceptable in light of the massive amounts of data that is being analysed but using this same metric as a proxy for the quality of the mentorship is questionable, especially in light of the gender bias in citations [6]. Following the authors' reasoning, they should only be able to measure the effect on scientific impact and not on mentor relationships. A measure of the quality of the mentorship could follow the principle of the survey and look at advice, recommendations, and networking received by the protégé, not only citation count.

As a final point in our methodological criticism, the gender was established using the genderize.io platform which, per their supplementary information, has surprising accuracy, which is good. However, categorizing it binarily does pose issues in that it does not represent gender variant researchers and, as they note, they have a $7 \%$ misclassification rate and a $47.71 \%$ unclassifiability rate [5]. In combination with the misidentification of mentor-protégé pairs (even assuming generalisation of the $0.007 \%$ the surveys represent), this means that the data is effectively reduced by $79.6 \%{ }^{1}$. This is not mentioned adequately in the paper.

\section{Political criticism:}

On these methodological grounds, our political criticism of the conclusions regarding gender is that they bear significant negative effects on the scientific community's work for diversity and equality as they seem unsupported.

\footnotetext{
${ }^{1} 3,000,000$ identified pairs $\cdot 42 \%$ correct pair identification $\cdot 52.29 \%$ gender classifiability rate $\cdot 93 \%$ gender classification $=20.42 \%$ accurately representative data
} 
As you state on the Nature Communications' Twitter page: "We reject any form of racism, and stand in solidarity with our Black authors and reviewers, as individuals and as a journal. We will strive to improve our support of diversity in science."

\section{(https://twitter.com/naturecomms).}

We argue that a big part of supporting this diversity in science is supporting the mission for equal choice and equal opportunity for males and females in the fields of STEM [7], where science is currently occupied by a majority of $70.7 \%$ males [8]. We do not believe that this paper supports that mission.

Despite the authors' awareness that gender equity is the mission of the community, as they note: "More broadly, the goal of gender equity in science, regardless of the objective targeted, cannot, and should not be shouldered by senior female scientists alone, rather, it should be embraced by the scientific community as a whole.", their conclusions regarding gender's effect on the mentor-protégé relationship seem inaccurate and reach beyond the conclusions their hypotheses represent:

"[...]mentors benefit more when working with male protégés rather than working with comparable female protégés, especially if the mentor is female."

"[...]current diversity policies promoting female-female mentorships, as well-intended as they may be, could hinder the careers of women who remain in academia in unexpected ways."

The social and financing gender bias in research is very likely to have driven the gender effect, but was barely discussed and not analysed. Arguing for more equality between the genders can address this issue, while representing the narrative that men are better mentors works against its solution.

In conclusion, the paper is methodologically limited in its inference capabilities in respect to the hypotheses it attempts to reach and from its analyses. This, in turn, allows proceeding papers to use the misguided conclusions, diminishing women's value in science by arguing that female mentors and protégés create less benefit to their partner, especially for women.

We add to the criticism you have already received (official open letters, comments on social media and on the paper) and we ask for a solution-focused outcome. In light of the previous points regarding the paper, we advocate that you publish a formal statement critiquing the publication of this study, both regarding the methods and the gender-related political issues it posits.

A simple retraction will not necessarily impact citation awareness of the issues in the paper as $80 \%$ of retracted papers are still used as supporting citations [9] and an official response from Nature will have a higher chance of impacting the sciences' approach to these issues in the future. We believe that one such action would align with Nature Communications' official values. 


\section{References:}

[1] S. M. lacus, G. King, and G. Porro, 'Causal Inference without Balance Checking: Coarsened Exact Matching', Polit. Anal., vol. 20, no. 1, pp. 1-24, 2012.

[2] V. Larivière, C. Ni, Y. Gingras, B. Cronin, and C. R. Sugimoto, 'Bibliometrics: Global gender disparities in science', Nat. News, vol. 504, no. 7479, p. 211, Dec. 2013, doi: 10.1038/504211a.

[3] Y. J. Xu, 'Gender Disparity in STEM Disciplines: A Study of Faculty Attrition and Turnover Intentions', Res. High. Educ., vol. 49, no. 7, pp. 607-624, Nov. 2008, doi: 10.1007/s11162-008-9097-4.

[4] E. H. Ecklund, A. E. Lincoln, and C. Tansey, 'Gender Segregation in Elite Academic Science', Gend. Soc., vol. 26, no. 5, pp. 693-717, Oct. 2012, doi: 10.1177/0891243212451904.

[5] B. AlShebli, K. Makovi, and T. Rahwan, 'Supplementary Information', p. 55.

[6] J. D. Dworkin, K. A. Linn, E. G. Teich, P. Zurn, R. T. Shinohara, and D. S. Bassett, 'The extent and drivers of gender imbalance in neuroscience reference lists', Nat. Neurosci., vol. 23, no. 8, Art. no. 8, Aug. 2020, doi: 10.1038/s41593-020-0658-y.

[7] E. Makarova, B. Aeschlimann, and W. Herzog, 'The Gender Gap in STEM Fields: The Impact of the Gender Stereotype of Math and Science on Secondary Students' Career Aspirations', Front. Educ., vol. 4, 2019, doi: 10.3389/feduc.2019.00060.

[8] UNESCO institute for statistics, 'Women in Science: Fact Sheet', Women in Science, Jun. 2019. http://uis.unesco.org/en/topic/women-science (accessed Nov. 21, 2020).

[9] J. Bar-llan and G. Halevi, 'Post retraction citations in context: a case study', Scientometrics, vol. 113, no. 1, pp. 547-565, 2017, doi: 10.1007/s11192-017-2242-0.

\section{Signatures:}

Students: Esben Kran Christensen, Alina Kereszt, Andrea Dioni Munksgaard, Anita Kurm, Anja Birch Alsøer, Anja Meerwald, Astrid Elmann Hansen, Bianka Szöllösi, Birgitte Dühring, Blanka Pálfi, Cecilie Vestergaard, Christoffer Jensen, David Fjendbo, Emily Virginia Hus, Emma-Louise Albæk Schnedler, Emma Hahn, Emma Lundkvist Søndergaard, Emma Olsen, Gacilda Anne, Gustav Helms, Helle Skjøth Sørensen, Jannik Wiggers, Jessica Clarke Rasmussen, Jonathan Hvithamar Rystrøm, Julia Jünger, Julie Svinth Nielsen, Jørgen Højlund Wibe, Karen Marie Gjerløff, Klara Krøyer Fomsgaard, Kristine Torp, Laura Emilie Hollænder, Laura Paulsen, Lina Elkjær Pedersen, Louie Juhl, Manon Éloïse Albeck Grandjean, Maria Nissen Byg, Maria Raunsbæk Thorsø, Maris Sala, Martine Lind Jensen, Mathilde Hyldal Eberholst, Matilde Sterup, Mia Jacobsen, Mille Nielsen, Mina Almasi, Nanna Marie Steenholdt, Nicoline Schmidt, Niels Krogsgaard, Nina C. H. Illum, Orla Mallon, Pernille Højlund Brams, Pernille Lærke Munk-Hansen, Sarah Hvid Andersen, Sara Viuf, Sebastian Scott Engen, Sigrid Agersnap Bom Nielsen, Sophie Stenderup Korch, Søren Orm Hansen, Thea Pedersen, Tobias Grønhøi Hansen, Veronika Juhasz, Victoria Hagelskjær Vilstrøm, Wilhelmina Axelgaard

Expressed support from the faculty: Andreas Roepstorff, Byurakn Ishkanyan, Christine Parsons, Cordula Vesper, Daina Crafa, Fabio Trecca, Joshua Charles Skewes, Micah Galen Allen, Mikkel Wallentin, Rebekah Brita Baglini 